\title{
FORMAÇÃO DE PROFESSORES NO RIO DE JANEIRO DURANTE O ESTADO NOVO
}

SONIA DE CASTRO LOPES

Professora Adjunta da Faculdade de Educação da Universidade Federal

do Rio de Janeiro

sm.lopes@globo.com

\section{RESUMO}

Articulado à temática da história das instituições educacionais, com ênfase na formação docente, este trabalho procura analisar as mudanças introduzidas no curso de formação de professores do Instituto de Educação do Rio de Janeiro durante o período do Estado Novo (1937-1945). Denominado Escola de Professores, quando da criação do Instituto em 1932 , o curso foi posteriormente incorporado à Universidade do Distrito Federal (1935) sob o nome Escola de Educação e habilitava professores primários e secundários em nível superior, conforme proposta do Manifesto dos Pioneiros (1932). Com a extinção dessa universidade, em 1939, e a transferência de diversos cursos para a recém-criada Universidade do Brasil, o Instituto de Educação foi excluído do novo projeto e passou a formar professores primários na modalidade normal, em nível médio. O artigo procura abordar a fase de transição pela qual a instituição passou, assinalando continuidades e mudanças em relação à proposta original para, em seguida, focalizar o momento de ruptura, em consequência da Lei Orgânica do Ensino Secundário (1942) que acarretou mudanças acentuadas no curso de formação de professores oferecido pela instituição. FORMAÇÃO DE PROFESSORES - HISTÓRIA DA EDUCAÇÃO - ESTADO NOVO 1937-1945

\section{ABSTRACT}

TEACHER EDUCATION AT THE INSTITUTE FOR EDUCATION OF THE RIO DE JANEIRO DURING THE NEW STATE PERIOD. Aligned with the theme of the history of educational institutions and focusing on teacher education, this article aims to assess the changes implemented in the Teacher Education Programme conducted by the Institute of Education of Rio de Janeiro, during the New State period (1937-1945). Initially called Escola de Professores ['Teachers' School'], when the Institute was founded in 1932, the Programme was later taken up by the Federal District University (1935,) under the name of Escola de Educação ['School of Education'] and provided primary and secondary school teachers with Higher Education, in compliance with the Manifesto of New Education Pioneers (1932). With the closing down of the Federal District University in 1939 and the transference of several courses to the recently established University of Brazil, The Institute of Education was excluded from the new project and was able only to provide primary teachers with secondary education certificates. This article exploits the transition that the Institute went through, highlighting changes and continuities in relation to its original proposition. The article then focuses on the unfolding of the rupture caused by the Secondary 
Education Organic Law (1942), leading to significant changes in the Teacher Education Programme offered by the institution.

TEACHER EDUCATION - HISTORY OF EDUCATION - ESTADO NOVO 1937-1945

Pretende-se analisar neste trabalho as mudanças introduzidas no curso de formação de professores oferecido pelo Instituto de Educação do Rio de Janeiro no período do Estado Novo (1937-1945). Denominado Escola de Professores quando criado em 1932, esse curso foi posteriormente incorporado à Universidade do Distrito Federal - UDF (1935) - sob o nome Escola de Educação e se propunha a habilitar professores primários e secundários em nível superior, conforme proposta do Manifesto dos Pioneiros ( I 932), que defendia a formação docente de todos os graus de ensino em nível universitário. Com a dissolução da UDF em 1939 e a absorção de diversos cursos pela Universidade do Brasil, criada pelo ministro Gustavo Capanema, o Instituto de Educação foi excluído do novo projeto e passou a formar professores primários na modalidade normal, em nível secundário.

Na historiografia da educação brasileira, muitos estudos têm-se debruçado sobre a temática da formação docente, elegendo como campo de suas investigações o Instituto de Educação do Rio de Janeiro. A maioria desses trabalhos situa as décadas de 1920 e 1930 como um momento de consolidação do campo educacional no Brasil, quando a questão da profissionalização docente assume grande destaque, graças aos projetos conduzidos por educadores ligados ao movimento da Escola Nova. São privilegiadas as reformas empreendidas por Fernando de Azevedo e Anísio Teixeira (Castro, 1986; Accácio, I993; Vidal, 200 I) no antigo Distrito Federal. Também o período compreendido entre 1945 e 1960, considerado "os anos dourados" da instituição, foi contemplado por algumas pesquisas como a de Martins (1996). Entretanto, o intervalo entre esses dois momentos, que corresponde à fase do Estado Novo, permanece como uma lacuna na historiografia sobre o tema.

$\mathrm{Na}$ realidade, talvez se possam observar mais continuidades do que rupturas no campo educacional brasileiro entre 1930 e 1960. Não apenas por ter sido o período em que o ensino sofre forte regulamentação por parte do Estado, mas, sobretudo, pela influência do ideário escolanovista com seu modelo de racionalidade científica aplicado tanto à organização escolar quanto ao processo ensino-aprendizagem (Saviani, 2004). Ainda que um olhar mais 
abrangente sobre a política educacional da época possa confirmar essa interpretação, é possível também perceber, numa análise mais restrita ao campo trabalhado, algumas rupturas que, se não contrariam, ao menos relativizam aquela matriz interpretativa já consolidada pelos especialistas.

Este artigo parte do pressuposto que várias estratégias foram desenvolvidas pelo poder instituído durante o período autoritário para apagar a participação dos educadores comprometidos com o "movimento da educação nova" no Instituto de Educação'. Merece especial destaque o Decreto-Lei n. I 56 /I 936 que, sem dúvida, teve como objetivo desmontar todo o projeto de formação de professores implementado no Instituto por Anísio Teixeira na reforma de 1932². Porém, o apagamento da memória sobre essa experiência tornou-se ainda mais perceptível após a saída de Lourenço Filho da direção geral da instituição, fato ocorrido na mesma época em que se decretava oficialmente o silêncio local - a censura - como uma das medidas restritivas impostas pelo governo autoritário que se consolidou a partir da decretação do Estado Novo.

Procurou-se dividir a exposição em dois momentos. Inicialmente, buscase focalizar a fase de transição pela qual a instituição passou, assinalando continuidades e mudanças em relação à proposta original de formação docente implementada pela reforma Anísio Teixeira. Em seguida, focaliza-se o momento de ruptura, em consequência da Lei Orgânica do Ensino Secundário (1942), que provocou mudanças acentuadas no curso de formação de professores, em

I. Refiro-me aqui às reformas de Fernando de Azevedo ( 1927- 1930) e Anísio Teixeira ( 193 I 1935) em relação à formação de professores. Nesta última, a antiga Escola Normal foi transformada em Instituto de Educação (1932) - um complexo educacional composto por uma Escola de Professores em nível superior, que formava professores primários ( 2 anos) e secundários (3 anos), e estabelecimentos anexos: pré-escola, escola primária e secundária que seriam os campos de aplicação dos futuros mestres. Em 1935, a Escola de Professores foi incorporada à Universidade do Distrito Federal, também criada por Teixeira. Interessa-nos particularmente neste artigo o curso de formação de professores primários que sofreu uma extensão, visto que pela reforma Fernando de Azevedo era cumprido em cinco anos após a escola primária. Já a reforma de Anísio exigia o curso secundário de seis anos antes do ingresso na Escola de Professores. Ver a respeito Lopes (2006).

2. O Decreto n. 156, de 30/12/1936, assegurava aos alunos matriculados até 1932, inclusive, na antiga Escola Normal que prestaram exame de admissão antes do Decreto n. 3.810 de 19/3/1932 (reforma Anísio Teixeira) o direito de concluírem o curso num período de cinco anos. Esses alunos seriam regidos pelo Decreto n. 3.28I de 23/l/l 928 (reforma Fernando de Azevedo), que previa um curso normal de cinco anos (ciclo geral propedêutico de três anos e ciclo especial ou profissional de dois anos) realizado após o curso primário. 
especial o Decreto n. 7.94I de 25/3/1943 que, ao regulamentar a reforma da escola secundária, conferiu uma nova estrutura ao curso do Instituto de Educação. Finalmente, infere-se que tais modificações acabaram por se consolidar com a promulgação da Lei Orgânica do Ensino Normal ( 1946 ), quando o novo curso adquire características bastante distintas do modelo anterior.

A pesquisa, que se insere na linha da história das instituições educacionais com ênfase na cultura escolar ${ }^{3}$, buscou privilegiar como fontes documentais as matrizes curriculares desses cursos, por entender que elas expressam em sua materialidade os diferentes modelos de formação docente existentes na instituição à qual nos reportamos. Parte-se da idéia de que o conjunto de conhecimentos e práticas presentes nesse tipo de documento é sempre selecionado em função de interesses de determinados grupos, como nos autorizam a pensar os trabalhos de Apple (1982, 1989) e de Goodson (1997). Foram utilizados também depoimentos de ex-alunas e ex-professores, pelos quais foi possível compreender de que maneira essas modificações foram sendo apropriadas e ressignificadas pelos atores sociais envolvidos no processo (Chartier, 1990).

\section{A DISSOLUÇÃO DA ESCOLA DE EDUCAÇÃO}

Entendemos que, assim como os projetos de memória são socialmente construídos, o mesmo ocorre com os "projetos de esquecimento", que se constroem pelo confronto das memórias em disputa ou entre grupos cujos embates produzem versões muitas vezes contraditórias do acontecido. $\mathrm{Na}$ opinião de Peter Burke (1992, p.249), os historiadores são justamente os "guardiões desses fatos incômodos", na medida em que tendem a recuperar os conflitos como objeto de pesquisa e sempre o fazem através de uma operação crítica que visa, em última análise, a deslegitimação da memória socialmente construída. Para tal, é preciso atentar para aspectos aparentemente irrelevantes, detalhes que muitas vezes passam despercebidos, lacunas e silêncios que se apresentam como indícios reveladores de acontecimentos sobre os quais não

3. Entende-se por cultura escolar "um conjunto de normas que definem conhecimentos a ensinar e condutas a inculcar, e um conjunto de práticas coordenadas a finalidades que podem variar segundo as épocas" (Julià, 200 I , p. I 0). Ainda segundo o autor, essas normas e práticas não podem ser analisadas se não levarmos em conta o corpo profissional dos agentes que são chamados a obedecer a essas ordens, bem como os dispositivos pedagógicos por eles utilizados. 
interessa à memória coletiva lançar luz. É preciso, antes de tudo, reconhecer que os acontecimentos passados foram vividos por indivíduos ou grupos que tinham concepções de mundo e projetos de sociedade bastante diferenciados.

Para Eni Orlandi, o silêncio sobre certos acontecimentos é, por excelência, matéria significante, o real do discurso, enquanto a linguagem produzida pelo homem tende a "domesticar a significação". "O silêncio não é visível, não é observável. Ele passa pelas palavras, só é possível vislumbrá-lo de forma fugaz, ele escorre por entre a trama das falas" (Orlandi, 1993, p.34). Longe de ser reacionário, como naturalmente se supõe, o silêncio é, na visão da autora, indício de resistência, pois mediando as relações entre linguagem e visão de mundo, resiste ao controle exercido pelo dominador e "significa de outras e muitas maneiras" (p.39). Muitas vezes, diante da interdição de se mencionar algo, somos impelidos a falar sobre "outras" coisas. Reside aí a dimensão política do silêncio, pois, se de um lado a censura opera sobre o dizível, de outro há a resistência expressada por uma política do silêncio que se instala de forma consensual e que significa aquilo que não se pode dizer. Ou seja, o que não se disse durante um período de censura, de alguma forma, produziu significado.

Após deixar oficialmente a direção geral do Instituto de Educação, em 31 de dezembro de 1937, Lourenço Filho foi substituído pelo professor Basílio de Magalhães que assumiu interinamente "não para servir ao governo, mas para servir ao Instituto" (Magalhães, 1995, p.6I), talvez na esperança de salvaguardar o trabalho desempenhado pelos renovadores na instituição. Ao que tudo indica, não foi muito feliz em sua curta administração, uma vez que a descontinuidade da filosofia pedagógica causou grandes transtornos ao curso de formação de professores. O catedrático, com muito bom humor, relata o clima de confusão reinante no Instituto nos primeiros meses de 1938:

O secretário de Educação, Sr. Paulo de Assis Ribeiro [...] fazia "trocas-baldocras" do "regulamento" em vigor no Instituto de Educação e, para dirigir a Faculdade Pedagógica (em que foi transformada a Escola de Professores), nomeou um monge beneditino, D. Xavier de Mattos, o qual redigia e firmava editais em tão mau vernáculo, que eu cheguei a bradar, alto e em bom som, que ele estava fazendo do Instituto de Educação um Instituto de Deseducação... pelo menos da língua portuguesa. Por cima de tudo, o Sr. Tristão de Ataíde, reitor da Universidade do Distrito Federal, ainda nos obrigava a trabalhar até altas horas da 
noite, visto como era ali que se realizavam os exames de admissão à Faculdade de Filosofia. (Magalhães, 1995, p.61)

Mesmo não sendo integrado à Universidade do Brasil, o Instituto de Educação continuou oferecendo o curso de formação de professores primários em dois anos que se seguiam à Escola Secundária de seis anos (cinco do ciclo fundamental mais um do ciclo complementar) ${ }^{4}$. Ou seja, em termos práticos não havia diferença, pois o total de tempo de estudos mantinha-se o mesmo. Curioso é que esse curso, ora era chamado de Normal, como aparece nos depoimentos das ex-alunas e na revista Instituto, cujo único volume foi publicado no final de 194I, ora era chamado de Curso de Formação de Professores Primários, conforme consta em documentos oficiais - históricos escolares da época - e na própria legislação municipal sobre formação docente ${ }^{5}$.

Delineava-se, assim, a tendência a estruturar a formação dos professores primários em nível secundário, com três anos de duração. A adaptação de estudos, realizada em função da Lei Orgânica do Ensino Secundário (1942), transformava a série única do antigo curso complementar no primeiro ano do Curso de Formação de Professores Primários, com caráter propedêutico, enquanto nos dois anos seguintes procurava-se conferir ao curso uma feição mais profissionalizante. A existência dessa dupla nomenclatura possibilita pensar que, para além da existência de concepções distintas para a formação dos profissionais, muito daquele passado recente da instituição "ficara perdido", como nos disse uma de nossas entrevistadas, ${ }^{6}$ ou era "silenciado para os novos alunos que chegavam", como sugeriu outra ${ }^{7}$.

4. $\bigcirc 2^{\circ}$ ciclo da escola secundária, denominado ciclo complementar pela reforma Francisco Campos (1931) compunha-se de dois anos, mas para efeito de prosseguimento de estudos na área de formação de professores no Instituto de Educação reduzia-se a apenas um ano. Estudavam-se neste ciclo complementar as seguintes disciplinas: Literatura, Inglês, Fisiologia Humana, Psicologia, Higiene e Puericultura, Sociologia, Estatística, Desenho, Educação Física e Alemão (facultativo). Cf. Decreto n. 3.810 de 19 de março de 1932, art. $4^{\circ}$ e $5^{\circ}$.

5. Organizado na administração do prefeito Dr. Henrique Dodsworth, sendo Secretário Geral de Educação e Cultura o Dr. José Pio Borges de Castro. Ver especialmente parte 9, título 2 "Da formação de professores" (p. 27|-76). Essa legislação diz respeito à situação vigente durante o ano de 1939, após o Decreto n. 1.063 de janeiro de 1939, que "dispôs sobre a transferência dos cursos da UDF para a Universidade do Brasil" (Distrito Federal, 1939).

6. Conforme depoimento de Aladyr Santos Lopes, formada em 1945, à autora em 27/9/2002.

7. Conforme depoimento de Nilza da Silva Camargo, formada em 1943, à autora em 31/10/200 I . 
O fato é que a imprecisão de termos reinava naquele Instituto no início dos anos 1940, a ponto de uma das alunas formadas na turma de 1942 e autora de um livro cujo título é emblemático - Normalista sim, com muita honra! - referir-se em um dos capítulos à Escola de Professores, à época já extinta, que ela e suas companheiras cursaram após a série complementar da escola secundária (Carneiro, 1990, p.8I). Aluna da mesma turma, Samaritana Vieira, afirma categórica que "nunca houve, como muitos diziam, curso superior para formar professores no Instituto". E enfatiza: "O que sempre existiu foi o curso normal"8.

Na fase mais autoritária do Estado Novo, na qual pontificaram a censura e a repressão política e que, não por acaso, coincidiu com a deflagração da Segunda Guerra Mundial e as manobras vitoriosas dos países do Eixo - entre 1939 e 1942 -, o Instituto foi dirigido por um militar, o Coronel Arthur Rodrigues Tito. Na memória da instituição, em parte construída pela obra do professor Balthazar da Silveira, a gestão do coronel Tito "trouxe vantagens ao conceituado educandário pelo prestígio que soube emprestar-lhe. Enérgico, mas afável, manteve uma disciplina louvável" (Silveira, 1954, p. 107).

\section{A ESTRUTURA CURRICULAR DO CURSO}

Na realidade, a estrutura curricular do Curso de Formação de Professores Primários - CFPP - no referido período sofreu poucas alterações em seu conteúdo, desaparecendo o sistema de organização trimestral, que deu lugar ao regime seriado?. Através de consultas que fizemos aos documentos de ex-alunas, encontrados no arquivo da instituiçãa, pudemos reconstituir as matrizes vigentes entre 1939 e 1942.

8. Samaritana Rocha Vieira, formada em 1943, em conversa informal com a autora em 27/6/2003.

9. No curso de formação de professores primários da Escola de Educação cada ano letivo se dividia em três períodos. Nos três primeiros trimestres ( $1^{\circ}$ ano) ofereciam-se, de forma intensiva, as matérias de Fundamentos da Educação e nos três últimos ( $2^{\circ}$ ano) a ênfase recaía na prática de ensino. Para integrar teoria e prática havia as chamadas "matérias de ensino", disciplinas ministradas por professores especializados nas quais não se dissociava o conteúdo da metodologia: Cálculo, Leitura e Linguagem, Literatura Infantil, Ciências Naturais e Estudos Sociais. Tais disciplinas começavam a ser oferecidas no $3^{\circ}$ trimestre do $1^{\circ}$ ano, tornando-se intensivas no $1^{\circ}$ trimestre do ano seguinte, de modo a articular as ciências da educação com a prática (Lopes, 2006, p. I I2). 
1939-1940: $1^{\circ}$ ano - Biologia Educacional, Psicologia Educacional, História da Educação, Leitura e Linguagem, Cálculo, Desenho, Música, Educação Física e Estatística; $2^{\circ}$ ano: Ciências Naturais, Estudos Sociais, Filosofia da Educação, Educação Cívica, Desenho, Canto Orfeônico, Educação Física e Prática de Ensino.

1941-1942: $1^{\circ}$ ano: Biologia Educacional, Psicologia Educacional, História da Educação, Educação Cívica, Leitura e Linguagem, Cálculo, Música, Educação Física e Estatística; $2^{\circ}$ ano: Ciências Naturais, Estudos Sociais, Filosofia da Educação, Educação Cívica, Orientação Escolar, Artes Aplicadas, Canto Orfeônico, Educação Física e Prática de Ensino. (Fonte: Históricos Escolares/Arquivo Geral do Instituto Superior de Educação - Iserj)

Para investigar a face interna do trabalho escolar no que diz respeito à construção do currículo, vale destacar os trabalhos de Apple (1982, 1989) para quem os currículos são concebidos, organizados e produzidos por indivíduos que têm interesses reais em condições políticas e econômicas definidas pelo mercado e pelo poder. Os estudos deste autor demonstram que o currículo é tanto mais eficaz quanto mais invisível, e que deve ser encarado e problematizado como um texto que influencia as práticas pedagógicas e vai sendo modificado ou adaptado no curso de sua aplicação. Assim, o currículo não se configura como um corpus de conhecimentos neutro, inocente e desinteressado, ou seja, o conhecimento presente no currículo é selecionado e resulta de um processo que reflete interesses de determinados grupos. Esses conhecimentos, tidos como legítimos, são sempre considerados "verdadeiros" em detrimento de outros. Ainda segundo a perspectiva do autor, para quem o currículo é sempre um espaço de lutas e resistências, logo, um espaço de poder, faz-se necessário indagar que interesses mobilizaram a seleção desses conhecimentos e quais as relações de poder envolvidas no processo de escolha de um currículo específico.

Apesar de não termos obtido informações sobre a carga horária semanal de cada disciplina, podemos chegar a algumas conclusões pelo estudo comparativo dessas matrizes com aquela vigente na instituição antes da extinção da Escola de Educação.

Em primeiro lugar, observa-se a supressão de uma disciplina que na época da Escola de Professores era oferecida em caráter intensivo. Trata-se de 
Sociologia Educacional, cuja inclusão justificava-se pela "necessidade de combinar os aspectos individuais da educação", representados pela grande carga de Psicologia - que, aliás, sempre foi a característica marcante do curso - "com a compreensão do meio social em que o futuro professor iria atuar" (CarvaIho, 1937, p.307-308). Ao que tudo indica, a Educação Cívica, introduzida a partir de 1940, passou a contemplar conteúdos antes pertinentes à cadeira de Sociologia, vistos agora sob uma ótica nacionalista, uma vez que colocava em relevo os principais valores cultivados pela ideologia do Estado Novo. Celso Kelly, regente das duas disciplinas, desenvolvia em suas aulas tópicos do programa cuja temática privilegiava questões como A família e a defesa nacional, As condições de eficiência no trabalho, As raças brasileiras, Vantagens e restrições da imigração no Brasil, entre outras (Prefeitura do Distrito Federal, 1940).

Na Secretaria de Educação do Distrito Federal foi criado, nessa época, um Departamento de Educação Nacionalista que exigiu a implementação em todas as escolas de um centro cívico, de modo que as aulas fossem articuladas às atividades dele. Em 1939, foi elaborado um programa de Educação Cívica para todas as escolas do Instituto, cuja bibliografia combinava clássicos de educadores ligados ao movimento da renovação educacional com breviários cívicos editados pelo Departamento de Imprensa e Propaganda - DIP -, que tinham como objetivo enaltecer a figura do presidente Vargas e legitimar o Estado Novo ${ }^{10}$.

No ano de 1940, fundou-se no Instituto o Centro Cívico Benjamin Constant, responsável pela organização de comemorações de caráter nacionalista em parceria com entidades conservadoras, como a Liga de Defesa Nacional. Logo depois, em 194I, seria lançada a revista Instituto, fundada por iniciativa do professor catedrático em Literatura, Júlio Nogueira, e redigida por alunos do ciclo complementar da escola secundária, recebendo colaborações de todas as escolas da instituição.

10. Dentre os livros publicados pelo DIP que constam da bibliografia e foram doados para a Biblioteca do Instituto, onde muitos se encontram até hoje, destacam-se: O presidente Getúlio Vargas e o Brasil de após 30; História de um menino de São Borja; Os grandes dias do Brasil Novo; Estudos e conferências; Problemas e realizações do Estado Novo; A Constituição de 10 de novembro explicada ao povo; Getúlio Vargas e a arte no Brasil; As idéias do presidente Getúlio Vargas; O Brasil novo, Getúlio Vargas e sua vida para as crianças brasileiras; A música nacionalista no governo Vargas; Pelo povo e para o povo; Para os trabalhadores (Fonte: Biblioteca Geral do Iserj). 
Além da disciplina de Educação Musical, acrescentou-se o Canto Orfeônico, justificado pela utilidade do canto e da música como fatores educativos. Defendia-se também o seu ensino por ser um "meio de renovação e de formação moral e intelectual [...] e uma das mais eficazes maneiras de desenvolver os sentimentos patrióticos do povo", como alegava o maestro Vieira Brandão em artigo na revista Instituto (Brandão, 1941, p. 16). Pregava-se o civismo na expressão mais ampla do termo, como "respeito aos nossos superiores, às nossas tradições étnicas de origem, ao trabalho disciplinado e realizador em todos os setores da vida originando maior capacidade de criação e espírito de iniciativa; a individualização dentro do coletivismo". Implantado nas escolas municipais do Distrito Federal sob orientação do maestro Villa-Lobos, com o objetivo de desenvolver a consciência cívica dos estudantes, o ensino do canto orfeônico tornou-se, durante o Estado Novo, um instrumento disciplinador que, assim como o regime, tentava ordenar, enquadrar as oposições, centralizando e imprimindo homogeneidade à cultura nacional (Lopes, 1998, p. I2I).

Considerando-se as novas tendências educacionais da época, observa-se também a inclusão da Estatística na nova matriz curricular, visto que a disciplina poderia contribuir para a formação da "consciência técnica" do professor, permitindo-lhe superar atitudes subjetivas e idealistas, bem como a melhoria do rendimento e produtividade de seu trabalho (Gandini, 1995).

Assim, se o comportamento era definido antecipadamente pela psicologia, a estatística atuava no sentido de classificar os indivíduos. Para Lourenço Filho (1940), esses recursos científicos e metodológicos de conhecimento e intervenção na realidade complementavam-se e eram necessários para a organização social. Em seu entender, "como fenômeno coletivo ou de massa, a educação só pode ser observada, descrita e definida, com os recursos da estatística", pois "as novas gerações se concretizam numa população que tem uma distribuição geográfica, e que se discrimina em grupos caracterizados segundo a idade, o sexo, a raça, a cor..." (Lourenço Filho, 1940, p. I37).

Por outro lado, a estrutura da seção das "matérias de ensino" (cálculo, leitura e linguagem, estudos sociais e ciências naturais) parece ter sido mantida, respeitando-se a indissociabilidade entre conteúdo e metodologia. Não se alterava também o oferecimento das disciplinas de fundamentos da educação no $1^{\circ}$ ano, para que as matérias de ensino fossem pensadas à luz do conhecimento pedagógico. Resguardava-se ainda a importância dispensada à Filosofia 
nos primeiros tempos da Escola, oferecida no final, como coroamento do curso. Todavia, observa-se um acúmulo de disciplinas no $2^{\circ}$ ano, deixando cada vez menos espaço para a Prática de Ensino, cuja carga horária provavelmente deve ter sofrido diminuição nesta nova estruturação curricular.

\section{O RETORNO AO CURSO NORMAL}

Se entre 1939, data em que o Instituto de Educação desvinculou-se da UDF, e 1942, o curso de formação de professores primários sofreu poucas alterações, após a promulgação da Lei Orgânica do Ensino Secundário (Decreto-Lei n. 4.244 de 9 de abril de 1942) ele seria totalmente reorganizado. Os dispositivos que regem essa nova orientação encontram-se no Arquivo Gustavo Capanema, num documento que se intitula: Algumas observações sobre o projeto de organização do Instituto de Educação do Distrito Federal (CPDOC/FGV: GC g 1939.05.12). Contendo na íntegra todas as observações feitas pelo ministro Capanema, esse documento seria transformado em decreto pelo prefeito da então capital do país (Decreto n. 7.94 I de 25/3/1943)".

As razões que justificam o decreto são várias. Na tentativa de padronizar o curso normal para todo o país, o que pouco tempo depois seria realizado através da Lei Orgânica do Ensino Normal, o decreto procura ordenar a confusão reinante eliminando a legislação heterogênea que resultou das múltiplas e sucessivas reformas por que passara o curso de formação de professores. Além disso, não se pode esquecer que a Lei Orgânica do Ensino Secundário ${ }^{12}$ introduziu dispositivos que impuseram modificações substanciais na legislação do Instituto, exigindo a sua adaptação à referida lei. Assim, cogitava-se oferecer, antes das matérias pedagógicas específicas do curso de formação de

II. O Decreto n. 7. 941, de 25 de março de 1943, foi assinado pelo prefeito Henrique Dodsworth, usando a atribuição que Ihe conferia a art. $7^{\circ}$, item IV, do Decreto-Lei n. 96, de 22 de dezembro de 1937. Encontra-se publicado no periódico Arquivos do Instituto de Educação, v. 2, n. I, p. 73-77, dez. 1945.

12. Pela Lei Orgânica do Ensino Secundário (Decreto-Lei n.4.244, de 9 de abril de 1942), o primeiro ciclo da escola secundária, agora denominado "ginásio", teria a duração de 4 anos, e o "curso colegial", antigo complementar, apresentando as modalidades clássico ou científico, dependendo do curso superior que se pretendesse cursar, duraria 3 anos. 
professores, uma preparação cultural básica constituída pelas disciplinas que integravam o curso ginasial.

Porém, as mudanças mais significativas voltadas para desestruturar a reforma docente de 1932 procuravam se legitimar evocando as origens, o que se comprova diante da defesa que se faz da volta da denominação Escola Normal, que "consagrada pela tradição é a que melhor se ajusta às finalidades específicas dos estabelecimentos de formação do professorado primário" (caput do Decreto n. 794I/1943).

O curso normal, no qual se ingressava após o ginásio, deveria ser feito em três séries, sendo que a primeira destinava-se a completar os estudos iniciados no curso ginasial e as outras duas procuravam oferecer as matérias próprias do ensino normal. A identidade da instituição, ainda que preservada em sua função primordial - formar professores primários para atender as escolas públicas do Distrito Federal - foi de certa maneira afetada, uma vez que o curso normal agora oferecido despojava-se do caráter profissional que lhe conferira a Reforma de 1932. Se o tempo de redução de estudos era, na verdade, irrisório - um ano apenas -, o espírito do curso seria substancialmente alterado.

O Instituto de Educação passaria a se constituir uma opção de qualidade para as moças de classe média que, desejando continuar seus estudos, ainda dispunham de um eficiente clássico ou científico. Inclusive, aquelas que concluíssem o curso clássico ou científico do Colégio do Instituto de Educação estariam dispensadas de cursar a la série normal, podendo matricular-se já na segunda série ${ }^{13}$. Já a matrícula aos cursos secundários em nível colegial - clássico ou científico - era limitada às alunas que haviam concluído o ginásio naquele estabelecimento, reservando-se 40 vagas para cada curso. Enquanto a forma de ingresso em qualquer um destes dois cursos era indicada por regulamento interno do Instituto, no caso do curso normal, o acesso era obtido imediatamente após a conclusão do ginásio.

Pelo artigo $3^{\circ}$, do Decreto n. 7.94 I//943, o Instituto de Educação seria restrito ao sexo feminino, garantindo-se assim a vitória de um princípio tão caro

13. Nessa época, a única forma de se chegar à universidade era mediante os cursos clássico ou científico. Nos anos 1950, pelas leis de equivalência, o curso normal passou a dar acesso ao curso de Pedagogia, e pela Lei de Diretrizes e Bases de 1961, todas as modalidades de ensino médio passaram a dar acesso ao curso superior, independentemente do curso escolhido. Ver a respeito Cunha (1983, p. | 33). 
aos segmentos mais conservadores da sociedade e que foi encampado pelo ministro Capanema em seu projeto para a educação das mulheres contido no Plano Nacional de Educação de $1937^{14}$.

O Instituto de Educação passava então a congregar o jardim de infância, a escola primária, um colégio secundário, uma escola normal, além dos cursos de especialização e aperfeiçoamento para os professores primários. Embora à primeira vista a estrutura organizacional apresentasse poucas diferenças, o novo currículo proposto para o curso normal era a evidência material, complementada por outras, de caráter simbólico ou legal, de estratégias adotadas deliberadamente com o objetivo de desestruturar a reforma de 1932, que resultou na transformação da antiga Escola Normal em Instituto de Educação.

A matriz curricular proposta pelo decreto de 1943 passaria a vigorar na instituição naquele mesmo ano, providenciando-se a devida adaptação de estudos. Por exemplo, os alunos aprovados nas disciplinas da $4^{a}$ série de 1942 passaram diretamente à la série da Escola Normal, os aprovados nas disciplinas da $5^{\mathrm{a}}$ série secundária tiveram direito à matrícula na $2^{\mathrm{a}}$ série do curso normal, bem como os concluintes da $6^{a}$ série, antigo curso complementar de um ano. Já os alunos aprovados nas disciplinas da Ia série do antigo Curso de Formação de Professores Primários passaram a constituir a $3^{a}$ série da Escola Normal. A entrada no Instituto continuava a efetivar-se somente na Ia série ginasial, mediante concurso e admissão, não sendo permitida transferência de outros estabelecimentos de ensino para quaisquer cursos do Instituto (Disposições transitórias do Decreto n. 7.94 I de 25/3/1943). Em razão do novo decreto, o currículo do Curso Normal do Instituto de Educação compreendia as seguintes matérias:

- $I^{\circ}$ ano: Português, Matemática, Geografia do Brasil, História do Brasil, Física, Química, Biologia, Higiene e Puericultura, Desenho, Educação Física, Música e Canto Orfeônico.

- $2^{\circ}$ ano: Biologia Educacional, Sociologia Educacional, História da Educação, Estatística Educacional, Metodologia da Linguagem, Metodologia do Cálculo, Trabalhos Manuais, Educação Física, Desenho, Música e Canto Orfeônico.

14. Sobre as idéias do ministro Capanema para a educação feminina ver Schwartzman, Bomeny, Costa (1984, especialmente o cap. 4). 
- $3^{\circ}$ ano: Higiene e Puericultura, Desenho, Educação Física, Música e Canto Orfeônico, Trabalhos Manuais, Filosofia da Educação, Metodologia das Ciências Naturais, Metodologia da História e Geografia, Legislação e Administração Escolar, Prática de Ensino. (Fonte: Distrito Federal, 1945)

Há algumas diferenças entre esta matriz adotada no Instituto de Educação em 1943 e o projeto de lei elaborado pelo ministério Capanema mais ou menos à mesma época, tendo como objetivo reorganizar o curso normal em todo o país. O projeto do ministro foi feito logo após a decretação da Lei Orgânica do Ensino Secundário e sugeria o programa mínimo a ser adotado em todo o território nacional ${ }^{15}$. A hipótese de Chervel (1990) é que uma das vantagens de estudar a história das disciplinas escolares é compreender a liberdade de manobra que tem a escola na escolha de seus componentes curriculares, ainda que essa liberdade seja, como diz o autor, uma meia-liberdade, limitada pelas pressões que sofre, tais como, a ação dos inspetores de ensino, os concursos e exames públicos, concorrência de outras escolas etc.

No caso específico do curso normal do Instituto de Educação essas pressões tinham menor peso, visto que esta era a única escola pública oficial na cidade do Rio de Janeiro a oferecer tal modalidade de ensino, o que talvez justifique sua relativa autonomia no sentido de implementar a matriz curricular que julgasse mais adequada. Além disso, por oferecer também um curso colegial nas modalidades clássico e científico, havia disponibilidade de professores de todas as áreas do conhecimento, o que, de certa forma, atendia aos objetivos explicitados no decreto de 1943, que via a I a série normal como um período de reforço à cultura geral fornecida pelo curso ginasial. Consequentemente, o currículo apresenta-se mais pulverizado devido à grande quantidade de disciplinas oferecidas, pois além das obrigatórias sugeridas pelo projeto ministerial, como

15. O Projeto de Decreto-Lei de Capanema, que reorganiza o curso normal e dá outras providências, sugere as seguintes disciplinas para o curso normal: $I^{\circ}$ ano: Português, Matemática, Ciências Físicas, Anatomia e Fisiologia Humanas, Higiene, enfermagem e educação sanitária, Trabalhos Manuais, Música, Desenho e Educação Física; $2^{\circ}$ ano: Higiene, enfermagem e educação sanitária, Trabalhos manuais, Música, Desenho, Educação Física, Psicologia Educacional, Sociologia Educacional, História e Filosofia da Educação, Metodologia e prática de ensino; $3^{\circ}$ ano: Higiene, enfermagem e educação sanitária, Música, Educação Física, Psicologia Educacional, Sociologia Educacional, História e Filosofia da Educação, Metodologia e prática de ensino (Fonte: Capanema, 1939). 
Português, Matemática e Ciências Físicas e Biológicas, no Instituto estudava-se também Geografia e História, especialmente da América e do Brasil.

A disciplina Higiene, enfermagem e educação sanitária, presente no projeto de Capanema, encontrava correspondência no currículo do Instituto de Educação na matéria Higiene e Puericultura, oferecida durante dois anos. Entretanto, o exagero da carga horária prevista no projeto de lei ( 5 horasaula no total) motivou sérias críticas de Fernando de Azevedo que, em carta a Lourenço Filho, expressou a dúvida "se as escolas normais se destinariam a formar professoras ou enfermeiras" (Azevedo, 1944).

A grande ausência no modelo curricular implementado no Instituto em 1943 são disciplinas equivalentes às "matérias de ensino", em que o conteúdo das disciplinas ensinadas no curso primário era associado à respectiva metodologia, enquanto que agora aparece totalmente desvinculado. No projeto elaborado pelo ministro, essa ausência torna-se ainda mais significativa, uma vez que "Metodologia" e "Prática de Ensino" apresentam-se como uma só disciplina, oferecida na $2^{\mathrm{a}}$ e $3^{\mathrm{a}}$ séries, num total de 15 horas-aula. Conferia-se assim às matérias indispensáveis para formar um professor primário o mesmo peso que a Higiene e Enfermagem, em que se ofereciam conhecimentos teóricos e práticos às futuras professoras para que tivessem condições de diagnosticar doenças como tuberculose, lepra, sífilis, tracoma, verminose, leishmaniose e malária, além de zelar pela higiene pessoal do aluno e prestar os primeiros socorros em caso de acidentes na escola ${ }^{16}$.

Comparando a nova matriz do Instituto às mais antigas, percebe-se claramente que, aos poucos, o curso vai se despindo de seu caráter profissional - a marca dos anos 1930 - para adquirir um caráter mais enciclopédico. Se, por um lado, isso se justificava por conta do encurtamento do $1{ }^{\circ}$ ciclo da escola secundária, que pela Lei Orgânica de 1942 passara a um período de quatro anos, por outro se percebe o curso mais superficial e pulverizado pela quantidade cada vez maior de disciplinas, dificultando o bom desempenho das alunas que desde o início do $3^{\circ}$ ano normal já trabalhavam como professoras na rede pública, sobretudo nos subúrbios mais distantes e até mesmo na zona rural ${ }^{17}$.

16. Conforme artigo $5^{\circ}$ do Projeto de Decreto-Lei que reorganiza o ensino normal (Capanema, 1939).

17. Todas as entrevistadas mencionaram o trabalho na rede pública em escolas afastadas do centro 
O espírito do curso, comparado ao da antiga Escola de Professores, alterou-se profundamente, o que levou a professora Iva Waisberg a criticar a estrutura curricular do curso normal na década de 1940:

A maioria de vós ainda não pode cristalizar uma consciência pública e profissional porque fostes sobrecarregados de erudição, neurotizadas pela competição por notas, entontecidas com a multiplicidade de técnicas de ensino de cada professor. [...] Durante longos anos [...] fostes submetidas a um currículo enciclopédico, a programas pletóricos, a horários estafantes que vos divorciaram completamente dos objetivos de um curso dessa natureza [...] Se o curso normal pretende realmente formar professores primários, é necessário que se lhe dê uma orientação prática, ativa, experimental. É preciso que as professorandas possam ter contato frequente com as realidades da escola e com as suas dificuldades. E este contato nunca será prematuro, devendo começar na la série normal, crescendo em intensidade pelas séries seguintes. (Waisberg, 1950, p.67-7I)

Convém esclarecer que na época em que o discurso foi proferido (dezembro de 1949), a matriz curricular do curso normal sofrera pequenas modificações em virtude da Lei Orgânica do Ensino Normal (Decreto-Lei n. 8.530, de 2/I/1946), mas que foi implementada no Instituto de Educação somente em 1947 ${ }^{18}$. Entretanto, tais mudanças apenas confirmaram a tendência de se conferir maior peso às disciplinas de formação geral, em detrimento das chamadas disciplinas específicas, o que distanciava cada vez mais o curso normal do modelo vigente na Escola de Professores quando da criação do Instituto de Educação.

A respeito do desvirtuamento dos objetivos do ensino normal, Anísio Teixeira não deixaria de fazer sua crítica no início da década de 1950. Em sua

no último ano do curso normal, além dos estágios e da exigência de boas notas nos testes e provas, pois o critério adotado para a escolha das escolas mais próximas era justamente o total de pontos obtido pelas alunas. Uma delas, em seu depoimento, chegou a mencionar o grande número de normalistas quer adoeciam, contraindo muitas vezes graves doenças pulmonares, o que levou o diretor do Instituto na época, o médico Leonel Gonzaga, a declarar-se contrário a essa prática. De acordo com depoimento de Aladyr Santos Lopes à autora, em 27 de setembro de 2002.

18. O Decreto n. 8.605-A, de 31/8//946, regulamentou o ensino normal no Instituto de Educação em conformidade com a Lei Orgânica do Ensino Normal. 
opinião, o curso normal estava descaracterizado como curso vocacional de habilitação ao magistério primário, na medida em que se operava a sua integração ao sistema de educação secundária do país, fazendo-se das escolas normais uma das formas de acesso ao ensino superior ${ }^{19}$. Assim, as escolas normais "se deixaram dominar pelo caráter de educação preparatória e não pela formação vocacional do mestre" (Teixeira, 1994. p. 124), falhando em seu duplo objetivo, pois nem ofereciam a formação cultural desejável ao ingresso em muitos cursos superiores, nem cuidavam com esmero da profissionalização dos professores.

Com a implantação da Lei Orgânica do Ensino Normal ( 1946) observase uma tendência cada vez maior do currículo em valorizar as disciplinas humanísticas em detrimento das disciplinas práticas. Foi esse curso de caráter ambíguo que prevaleceu na Escola Normal do Instituto de Educação até o início dos anos 1960, quando então entrou em vigência a Lei de Diretrizes e Bases da Educação Nacional (n. 4.024 de 20/I2/196I). Curiosamente, este é o período que a memória coletiva registra como a fase áurea da instituição, origem do mito dos anos dourados, evocado com orgulho por muitos dos atuais professores, na condição de ex-alunos.

\section{ROMPENDO O SILÊNCIO}

Em dezembro de 1945, logo após a derrubada do regime de exceção que vigorou por oito anos no país, vários professores do Instituto, reunidos no auditório que acabara de ser batizado com o nome de um dos responsáveis pela construção da obra - Fernando de Azevedo -, romperam o silêncio. De acordo com o discurso da professora Iva Waisberg, colocava-se um ponto final naquela "longa noite de confusão" que se abatera sobre a instituição durante todos aqueles anos.

Francisco Venâncio Filho, signatário do Manifesto dos Pioneiros e amigo particular de Fernando de Azevedo, tinha assumido a direção geral do Instituto

19. Na década de 1950, uma das "leis de equivalência", a Lei n I.821, de março de 1953, determinava a possibilidade de inscrição nos exames vestibulares ao ensino superior aos egressos do $2^{\circ}$ ciclo dos cursos industriais, agrícolas e normais, restringindo, porém, pelo Decreto $\mathrm{n}$ 34.330, de outubro do mesmo ano, o acesso das normalistas aos cursos de Pedagogia e Letras da Faculdade de Filosofia, sendo posteriormente, em 1954, permitido o acesso aos cursos de Geografia e História da mesma faculdade (Cunha, 1983). 
de Educação. Seu empenho em registrar a homenagem dos professores ao idealizador do prédio que abrigaria a "nova" Escola Normal pode ser mensurada pela publicação de um número particularmente emblemático dos Arquivos do Instituto de Educação ${ }^{20}$, levando-se em conta a época e circunstâncias em que foi produzido. Constam no periódico diversos artigos rememorando o "movimento dos renovadores", do qual o Instituto seria o produto, além do relato de discursos proferidos por alguns professores da instituição saudando o homenageado.

Um destes discursos, feito pela professora Iva Waisberg, na época jovem professora de Psicologia do curso normal, faz uma alusão direta ao silêncio imposto em relação às experiências dos pioneiros naquela instituição:

Estaríamos proibidos de sentir júbilo se a doce, inebriante e quem sabe, curta liberdade, não tivesse revivido entre nós. Mas veio, e dure o que durar, sorvamola ansiosamente porque talvez venhamos a precisar de toda coragem para um novo silêncio. Foi essa aragem de liberdade que me fez aceder imediatamente ao desejo que Venâncio Filho manifestou de ouvir a geração de discípulos de Fernando de Azevedo - nosso pioneiro, nosso mestre, amigo caríssimo, apesar do convívio entrecortado de longas ausências. [...] Mas a quem devemos a estrutura moral e profissional que nos permitiu atravessar a longa noite da confusão unidos pelo mesmo vínculo profundo de uma formação espiritual? Devemo-la aos pioneiros da educação, a Anísio Teixeira, Sampaio Dória, Roquette Pinto, Delgado de Carvalho, Almeida Júnior e à frente de todos, como um paladino, esteve o nosso homenageado de hoje. (Waisberg, 1945, p.90)

Venâncio Filho e o homenageado também lembraram em seus discursos a "lucidez transformadora" de Anísio Teixeira e o empenho de Lourenço Filho em tornar concreto, ainda que por pouco tempo, o ideal de educação dos pioneiros naquela instituição. A unidade do movimento, pela qual Fernando de Azevedo tanto se empenhara, ficaria seriamente comprometida a partir das prisões, exílios forçados, cooptação e tantos outros processos de esfacelamento a que o grupo foi submetido.

20. Arquivos do Instituto de Educação, v. 2, n. I, dez. 1945. Depois de uma lacuna de oito anos, os Arquivos... voltaram a ser publicados entre 1945 e 1960: v. 2, n. I. dez. 1945; v. 2, n. 2 jun. 1949; v. 2, n. 3 jun. 1950, v. 3, n. I, 1956; e v. 3, n, 2, 1960. 
Nessa comemoração, Venâncio Filho justifica sua passagem pela direção do Instituto para "pagar a dívida que esta casa tem para com o seu criador" (Venâncio Filho, 1945, p.8I). A homenagem ocorre no dia 8 de dezembro de 1945, ocasião em que se deu ao auditório o nome do educador e procedeuse à inauguração solene de seu retrato na sala da diretoria. Discursaram nessa noite a professora Maria Reis Campos, que havia sido sua colaboradora na reforma de 1928, Nóbrega da Cunha, diretor do Departamento Nacional de Educação, em nome dos educadores brasileiros, Fernando Raja Gabaglia, secretário de Educação e Cultura do Distrito Federal, e Iva Waisberg, professora do curso normal, em nome da geração de discípulos do professor Fernando de Azevedo.

Diplomada pela primeira turma da Escola de Professores, em 1934, Iva Waisberg foi também pioneira ao colar grau na única turma formada pela Universidade do Distrito Federal em 1938, sendo inclusive escolhida como a oradora do grupo. No discurso daquela noite, ela se descreve como "monumento vivo da história admirável e anônima de um grupo de jovens que aprendeu a viver pensando acima de tudo o bem coletivo, a objetividade, o espírito de autocrítica, o amor ao estudo e a análise dos problemas nacionais", declarando-se representante de uma geração diretamente influenciada pelo Movimento de Educação Renovada. Referindo-se à "década sombria" que tinham acabado de viver, perturbada pelo "fascismo internacional e nacional", lamenta a destruição da obra "sinceramente democrática iniciada em 1927 no Distrito Federal com Fernando de Azevedo e continuada por Anísio Teixeira." E conclui, assumindo o compromisso com a continuação da obra: "Nós nos espelhamos na alma dos nossos mestres e eles se perpetuarão através de cada um de nós" (Waisberg, 1945, p. 93-94).

A cerimônia especial em que se homenageava Fernando de Azevedo no Instituto de Educação celebrava o fim da "longa noite da confusão" imposta pelo Estado Novo, recém-extinto. Diversos professores que tinham sido afastados por razões políticas retornavam ao convívio de seus companheiros, reassumindo a docência. Destacamos particularmente os casos de Edgard Sussekind de Mendonça, Mário Paulo de Brito e José Paranhos Fontenelle.

Aproveitando-se da "doce e inebriante liberdade", os sobreviventes e seguidores do movimento renovador tentavam reanimá-lo. É visível a preocupação de reestruturá-lo através do discurso, de recuperar, de forma nostálgica, 
a unidade que se perdera. Para Nora, o tempo dos "lugares de memória" é esse momento preciso em que "desaparece um imenso capital que nós vivíamos na intimidade de uma memória para só viver sob o olhar de uma história reconstruída" (Nora, 1993, p. 12), sendo uma característica marcante desses lugares justamente a "sua derrota em se tornar aquilo que quiseram seus fundadores, pois se estivéssemos ainda hoje vivendo sob seu ritmo, teriam perdido a virtude de lugares de memória" (p.23).

O período mediado entre 1945 e 1960 é quase sempre identificado como a fase áurea da formação docente no Instituto de Educação do Rio de Janeiro, constatando-se nessa época uma verdadeira efervescência cultural com o reaparecimento das edições dos Arquivos..., da revista de alunas Normalista, e uma efetiva atuação do Grêmio Ruy Barbosa orquestrando atividades culturais como cinema e teatro (Martins, 1996). Diversos membros do corpo docente, a exemplo da professora Iva, cultivavam a esperança de revitalizar a proposta educacional implementada por Anísio Teixeira no início dos anos 1930 . O otimismo em relação ao regime democrático que ora se instalava no país justificava essas esperanças, levando-os a acreditar num retorno aos tempos iniciais, em que seria possível imprimir um caráter científico e democrático ao curso de formação de professores.

Embora a Constituição Federal de 1946 restabelecesse uma orientação descentralizadora, deslocando a competência da organização dos cursos de formação de professores para o âmbito dos estados (Tanuri, 2000), o curso normal do Instituto de Educação do Rio de Janeiro pautou-se pelo Decreto n. 8.605-A, de 31/8/1946, que seguia à risca as determinações contidas na Lei Orgânica ${ }^{21}$. Com um currículo enciclopédico, constituído por uma grande quantidade de disciplinas de caráter propedêutico, jamais retomaria o espírito que pretendeu imprimir a ele a reforma de Anísio Teixeira nos anos de 1930.

Hoje, diante de uma lei de ensino que preconiza a formação de professores de todos os níveis em cursos superiores, é oportuno refletir sobre a história do Instituto de Educação do Rio de Janeiro como uma experiência

21. A Lei Orgânica do Ensino Normal (Decreto-Lei n. 8.530, de 2/1/1946) tinha, de fato, um caráter menos autoritário que as demais por ter sido assinada logo após o final da ditadura Vargas. Ainda assim, mantinha a ingerência do governo central em relação aos cursos normais estaduais preservando a orientação centralizadora da administração estadonovista. Ver a respeito Tanuri (2000, p. 75). 
pioneira nesse sentido. Considerado por muito tempo uma instituição modelar, o Instituto não escapou, nas últimas décadas, às sucessivas crises que afetaram o ensino público de maneira geral e os cursos de formação de professores, em especial. Tornou-se, assim, "lugar de memória" da formação docente, porém, incapaz de se reconhecer nos projetos de seus criadores.

\section{REFERÊNCIAS BIBLIOGRÁFICAS}

ACCÁClO, L. Instituto de Educação do Rio de Janeiro: a história da formação do professor primário (1927-37). Rio de Janeiro, 1993. Dissert. (mestr.) Faculdade de Educação da Universidade Federal do Rio de Janeiro.

APPLE, M. Currículo e poder. Educação \& Realidade, Porto Alegre, v. 14 n.2, p. 46-57, 1989. Ideologia e currículo. São Paulo: Brasiliense, 1982.

BURKE, P. O Mundo como teatro: estudos de antropologia histórica. Lisboa: Difel, 1992. A História como memória social, p. 235-251. ( Trad.: Wanda Maria Anastácio)

CARNEIRO, M. E. Normalista sim, com muita honra! Rio de Janeiro: 1990.

CASTRO, L. V. de. Uma escola de professores: formação de docentes na reforma Anísio Teixeira (1931-35). Rio de Janeiro, 1986. Dissert. (mestr.) Departamento de Educação, Pontifícia Universidade Católica do Rio de Janeiro.

CHARTIER, R. A História cultural entre práticas e representações. Lisboa: Difel, 1990.

CHERVEL, A. História das disciplinas escolares: reflexões sobre um campo de pesquisas. Teoria \& Educação, n. 2, p. 177-229, 1990.

CUNHA, L. A. A Universidade crítica. Rio de Janeiro: Francisco Alves, 1983.

GANDINI, R. Intelectuais, Estado e Educação: RBEP (1944-52). Campinas: Unicamp, 1995. GOODSON, I. A Construção social do currículo. Lisboa: Educa, 1997.

JULIÀ, D. A Cultura escolar como objeto histórico. Revista Brasileira de História da Educação, n. I, p. 9-44, jan./jun. 2001.

LOPES, S. C. Nacionalismo musical: arte e política na era Vargas. Dia-logos, ano 2, n.2, p. 119-132, 1998.

Oficina de mestres: história, memória e silêncio sobre a Escola de Professores do Instituto de Educação. Rio de Janeiro: DP\&A; Faperj, 2006. 
LOURENÇO FILHO, M. B. Estatística e educação. Revista Brasileira de Estatística, v. I , n. I , jan./mar. 1940.

MAGALHÃES, B. de. Trecho de um capítulo de minhas memórias. In: VENÂNCIO FILHO, A. (org.) Venâncio Filho, um educador brasileiro. Rio de Janeiro: Nova Fronteira, 1995.

MARTINS, A. M. Dos anos dourados aos anos de zinco: análise histórico-cultural da formação do educador no Instituto de Educação do Rio de Janeiro. Rio de Janeiro, 1996. Tese (dout.) Universidade Federal do Rio de Janeiro.

NORA, P. Entre memória e história: a problemática dos lugares. Projeto História, São Paulo, n. 10, p. 7-28, dez. 1993. (Trad.: Yara Khoury)

ORLANDI, E. As Formas do silêncio. 2. ed. Campinas: Unicamp, 1993.

SAVIANI, D. O Legado educacional do "longo século XX" brasileiro. In: SAVIANI, D. et al. O Legado educacional do século XX no Brasil. Campinas: Autores Associados, 2004. p. I I-57. (Col. Educação contemporânea)

SCHWARTZMAN, S.; BOMENY, H.; COSTA, W. Tempos de Capanema. Rio de Janeiro: Paz e Terra, 1984.

SILVEIRA, A. B. da. História do Instituto de Educação. Distrito Federal: Gráfica do Departamento de Educação e Cultura, 1954.

TANURI, L. História da formação de professores. Revista Brasileira de Educação. São Paulo, n. |4, p. 61-88, maio/ago. 2000.

TEIXEIRA, A. Educação não é privilégio. Rio de Janeiro: UFRJ, 1994.

VIDAL, D. O exercício disciplinado do olhar: livros, leituras e práticas de formação docente no Instituto de Educação do Distrito Federal (1932-1937). Bragança Paulista, Edusf, 200 I . (Col. Estudos CDAPH, Série Historiografia)

\section{DOCUMENTAIS}

AZEVEDO, F. Carta a Lourenço Filho datada de 26 de janeiro de 1944. Arquivo Lourenço Filho. (CPDOC / FGV. LF c 36.1 I.21. Rolo I, fot. 221-26)

BRANDÃO, J. V. Panorama do ensino da Música na concepção moderna de educação. Revista de alunos Instituto, v. I, n. I, p. 16-17, out. /dez. 1941.

BRASIL. Decreto-lei n.4.244, de 9 de abril de 1942: lei orgânica do ensino secundário. Rio de Janeiro, 1942. 
CAPANEMA, G. Algumas observações sobre o projeto de organização do Instituto de Educação do Distrito Federal. Arquivo Gustavo Capanema. CPDOC/FGV. (GC g 1939.05. 12. Rolo 54, fot. 605- 648)

CARVALHO, D. de. Programa de sociologia educacional. Arquivos do Instituto de Educação, v. I, n. 3, p. 307-308, mar. 1937.

DISTRITO FEDERAL. Prefeitura. Decreto n. 8.605-A, de 3 I de agosto de 1946. Regulamenta o curso normal do Instituto de Educação do Rio de Janeiro.

Prefeitura. Decreto n. 7.94I, de 25 de março de 1943. Arquivos do Instituto de Educação, v. 2, n. I, p. 73-77, dez/1945.

Prefeitura. Decreto n. 3.810, de 19 de março de 1932. Transforma em Instituto de Educação a antiga Escola Normal e estabelecimentos anexos.

Prefeitura. Leis, decretos e regulamentos municipais relativos ao sistema escolar do Distrito Federal e sua administração vigente em 31 - 12-1939.

Prefeitura. Secretaria de Educação: Programa de Educação Cívica para o Instituto de Educação e estabelecimentos de educação técnico-profissional, 1940.

VENÂNCIO FILHO, F. Discurso de posse na direção do Instituto de Educação. Arquivos do Instituto de Educação, v. 2, n. 4, p. 79-82, dez/1945.

WAISBERG, I. Discurso pronunciado no Teatro Municipal paraninfando as professorandas de 1949 do Instituto de Educação. Arquivos do Instituto de Educação, v.2, n. 3, p. 67-7I , jun./I 950.

Saudação a Fernando de Azevedo. Arquivos do Instituto de Educação, v. 2,

n. I, p.94, dez. 1945.

Recebido em: março 2007

Aprovado para publicação em: junho 2009 